\title{
Critical Evaluation of the Agronomic Effectiveness of Recovered Phosphate Fertilizer Produced From Incinerated Sewage Sludge Ash
}

Le FANG ( $\square$ fang.le@connect.polyu.hk)

Beijing Normal University - Zhuhai Campus

Qiming Wang

The Hong Kong Polytechnic University

Jiang-shan Li

Chinese Academy of Sciences

Chi Sun Poon

The Hong Kong Polytechnic University

\section{Research Article}

Keywords: recovered phosphate fertilizer, incinerated sewage sludge ash, agronomic analysis, heavy metals, waste management

Posted Date: July 19th, 2021

DOI: https://doi.org/10.21203/rs.3.rs-709653/v1

License: (c) (i) This work is licensed under a Creative Commons Attribution 4.0 International License. Read Full License 


\section{Abstract}

Phosphorus (P) recovery from incinerated sewage sludge ash (ISSA) has been extensively investigated, and various recovered phosphate fertilizers (RPFs) have been produced. In this study, three RPFs (calcium phosphate compounds (CaP), struvite (SP), and P-loaded biochar (BP)) produced from ISSA were characterized and their agronomic effectiveness were verified by pot experiments with the cultivation of choy sum (Brassica campestris L. ssp. Chinensis var. utillis Tsen et Lee) and ryegrass (Lolium perenne L.). The SP has the highest P purity while the BP has the most complex P species. And the plant growth results showed that the RPFs greatly facilitated plant growth and demonstrated superior/comparable effects to those of MP/CoF. In general, choy sum fertilized with SP showed the best effect due to the Mg involved and the high $\mathrm{P}$ purity of SP, while ryegrass fertilized with BP performed the best among all of the groups because of the additional nutritional elements and the high P availability of BP. Additionally, the accumulation of heavy metals in the plants under all conditions did not exceed the limits stipulated in the regulations. These results indicate that recovering $P$ from ISSA is an attractive technology to produce $P$ fertilizers, which can alleviate both the scarcity of phosphate resources and the burden of ISSA management.

\section{Introduction}

Phosphorus $(P)$ is crucial for the growth of plants, and their continual productivity requires the input of $P$ fertilizers (Hilt et al., 2016). The manufacture of conventional P fertilizer relies on exploiting phosphate rock, the source of which has continued to shrink in recent years (Rosemarin and Ekane, 2016). With the decline in the phosphate rock reserve, $\mathrm{P}$ fertilizer will not be as economically viable as previously (Kataki et al., 2016; Li et al., 2019; Walan et al., 2014). The recovery of $P$ from secondary $P$ sources can not only cater to approximately $22 \%$ of the global demand but also optimize the balance of inputs/outputs of $P$ (Gupta et al., 2014; Nesme and Withers, 2016).

Various secondary P sources have been explored in P-containing wastes, such as animal manures, wastewater, sewage sludge and incinerated sewage sludge ash (ISSA) (Antonini et al., 2012; Börjesson and Kätterer, 2018; Cordell et al., 2009; Montemayor et al., 2019; Senthilkumar et al., 2014). Among these, ISSA is a byproduct generated from sewage sludge incineration plants and it exhibits a high P recovery potential (Donatello and Cheeseman, 2013; Petzet et al., 2011). With more countries applying incineration methods to handle sewage sludge, ISSA is an important waste with a high P content. However, direct use of ISSA as fertilizer is impossible due to its high heavy metal contents and poor $\mathrm{P}$ bioavailability (Gorazda et al., 2016; Herzel et al., 2016). Previous studies have recovered various phosphate fertilizers, but their $\mathrm{P}$ availability for plants and the impact of their heavy metal content on soil or plants has barely been discussed (de-Bashan and Bashan, 2004; Krüger, 2016; Lee et al., 2018). The plant availability of RPFs is determined by the desorption/release of $\mathrm{P}$ caused by flushing and interactions with microbes, soils and plants (Cavalcante et al., 2018; Luo et al., 2021). 
Heavy metals, such as $\mathrm{Zn}, \mathrm{Cu}$, Co and $\mathrm{Ni}$, are essential microelements for plant growth, but their excessive application is toxic (DeForest and Meyer, 2015; Rathika et al., 2020; Weissengruber et al., 2018). Metals are adsorbed by roots and transported in the form of metal complexes or free metals across the root cortex to the stele (Niu et al., 2011; Zhao et al., 2018). Their translocation from RPFs to plants eventually causes them to accumulate through food chains, posing a risk to the health of animals and humans ( $\mathrm{Li}$, Z. et al., 2014; Yu et al., 2012; Zhao et al., 2018). However, the pros of applying RPFs far outweigh their cons. In addition to alleviating the problem of a finite supply of phosphate rock, RPFs are normally recovered from wastes; thus, the pollution caused by these wastes is reduced significantly. In addition, some RPFs, such as biochar, enhance the water retention effect of soil, mitigate metal pollution, adjust the $\mathrm{pH}$ of the soil, etc. (Steinbeiss et al., 2009; Wang et al., 2019). As such, it is difficult to determine the effect of RPFs only through the existing accepted criteria due to their complexity (Kratz et al., 2019; Meena et al., 2019). Hence, plant growth tests are especially important in exploring new kinds of RPFs, which truly reflect their behaviours in soil and their applicability for agricultural production.

Three kinds of phosphate fertilizers (RPFs) can be recovered with three dominant wet-extraction methods of ISSA: adding ammonia gas/liquid to the purified acid extract of ISSA; adding calcium to the purified acid extract of ISSA; and using modified biochar to adsorb P from the acid extract of ISSA (Fang et al., 2014; Franz, 2008; Lemming et al., 2017; Liang et al., 2019; Petzet et al., 2012; Xu et al., 2012; Yao et al., 2013; Zin et al., 2019). These produce three kinds of RPFs: struvite (SP) dominantly contains magnesium ammonium phosphate hexahydrate $\left(\mathrm{NH}_{4} \mathrm{MgPO}_{4} \cdot 6 \mathrm{H}_{2} \mathrm{O}\right)$ and is a slow-release fertilizer with high purity (Wang et al., 2018); calcium phosphate fertilizer (CaP) is a precipitate from the P-extract that contains Ca$\mathrm{P}$ and Al-P along with other metals (Fang et al., 2018a); and P-loaded biochar (BP) is a kind of organic matrix that has been shown to enhance the properties of soils (Shakoor et al., 2021). Although the $P$ content of these RPFs has been verified, systematic study of their agronomic effectiveness is still lacking.

The present study was therefore designed to evaluate the agronomic effectiveness of these three RPFs produced from ISSA as sources of $P$ in two different systems for the cultivation of choy sum (Brassica campestris L. ssp. Chinensis var. utillis Tsen et Lee) and ryegrass (Lolium perenne L.). The main objectives of this study were 1 ) to characterize the RPFs produced from ISSA;2) to evaluate the agronomic effectiveness of the RPFs through pot trial tests for the cultivation of choy sum via hydroponics and ryegrass via soil culture experiments; and 3) to analyse the levels of nutrients and the accumulation of heavy metals in the plants.

\section{Materials And Methods}

Characteristics of RPFs

Three kinds of RPFs are produced from Hong Kong ISSA by different methods, and their detailed production process can be found in the supplementary information (Text S1) (Fang et al., 2019; Fang et al., 2018a; Wang et al., 2018). In short, BP was obtained by adsorption of P from acid extraction of ISSA by $\mathrm{Mg}$-dosed sugarcane biochar $\left(700^{\circ} \mathrm{C}\right.$ for 1 hour with $\mathrm{MgCl}_{2}$ amendment). CaP was precipitated from 
the $\mathrm{P}$ extract by adding $\mathrm{Ca}(\mathrm{OH})_{2}$ to increase the $\mathrm{pH}$ of the $\mathrm{P}$ extract to 4 . SP was produced through struvite crystallization of the $\mathrm{P}$ extract prior to purification by cation exchange resin (CER).

For characterization of the RPFs, they were digested using aqua-regia, and then $\mathrm{P}$ and the heavy metal concentrations in the filtrates were measured using a spectrophotometer and inductively coupled plasma/optical emission spectroscopy (ICP-OES, FMX 36, SPECTROBLUE), respectively. The chemical compositions of these three fertilizers are shown in Table 1. The crystalline phases in the three dried and milled RPFs were analysed by X-ray diffraction (XRD, Rigaku Smartlab, Japan) using CuKa radiation ( $\lambda=$ $1.54059 \AA$ ) at $40 \mathrm{kV}$, and $30 \mathrm{~mA}$ was used for scanning. With scanning increments of $0.02^{\circ}$ and a counting time of 2 seconds per step, the peaks were verified in the range of 10 to $70^{\circ} 2 \theta$. The micromorphology of the three RPFs were identified by scanning electromicroscopy (Tescan-vega3) with energy dispersive $\mathrm{X}$-ray spectroscopy (SEM-EDX).

Table 1

$\mathrm{pH}$ and contents of SP, MP and BP

\begin{tabular}{|c|c|c|c|c|c|c|c|}
\hline \multirow[t]{2}{*}{ Items } & \multirow[t]{2}{*}{$\mathrm{pH}$} & \multirow[t]{2}{*}{ Major elements $(\mathrm{mg} / \mathrm{g})$} & \multicolumn{5}{|c|}{ Heavy metal $(\mathrm{mg} / \mathrm{kg})$} \\
\hline & & & As & $\mathrm{Cd}$ & $\mathrm{Cu}$ & $\mathrm{Pb}$ & $\mathrm{Zn}$ \\
\hline SP & 9.5 & $\mathrm{Mg}$ (62.75), N (52.16), P (63.14), Ca (52.12). & 9.3 & N.D. & 26.6 & 54.7 & 37.6 \\
\hline $\mathrm{CaP}$ & 6.5 & $\begin{array}{l}\mathrm{Ca}(251.78), \mathrm{S}(130.71), \mathrm{P}(61.92), \mathrm{Al} \\
(52.19), \mathrm{Fe}(16.01) .\end{array}$ & 18.0 & 19.0 & 48.0 & 120.0 & 136.0 \\
\hline $\mathrm{BP}$ & 7.2 & $\begin{array}{l}\mathrm{C}(410.1), \mathrm{Mg}(42.87), \mathrm{P}(30.86), \mathrm{Al}(18.12) \\
\mathrm{Ca}(17.21), \mathrm{K}(3.61)\end{array}$ & 13.0 & 10.0 & 60.5 & 130.0 & 215.5 \\
\hline
\end{tabular}

Pot experiment and determination of the physicochemical characteristics of the plants

Choy sum, one of the major vegetable crops in southern China, was cultivated in hydroponics (Chen et al., 2017), and ryegrass was cultivated in soil. Hydroponic and soil cultivation were carried out separately as described in the supplementary information (Text S2). The P dose in hydroponic and soil cultivation refers to the contents of Hoagland's nutrient contents and a dose of $5.64 \mathrm{gP} \mathrm{m}^{-2}$ (Fernandez, 2021). The visual growth conditions of the choy sum/ryegrass were recorded using smartphone cameras. For the choy sum, the number of leaves and the maximum leaf size were recorded on the 7th, 13th, 21st and 30th days. For the ryegrass, the growth status was recorded at days 30 and 40.

After cultivation, the length (distance from the leaf base to the leaf tip) of the leaf, fresh weight and dry weight $\left(105^{\circ} \mathrm{C}\right.$ for 2 hours, and $60^{\circ} \mathrm{C}$ until constant weight) of the shoot were measured (Hao et al., 2018). The chlorophyll contents of the plants were determined using a spectrophotometer after 24 hours of extraction of the cut leaf using 95\% ethanol (Wang et al., 2019). Referring to NIST SRM 2711a (Cui et al., 2018; Li, J. et al., 2014), total digestion was carried out on ball-milled plant samples by using concentrated $\mathrm{HNO}_{3} / \mathrm{HClO}_{4}(4: 1)$ on a hot plate, and then the elemental concentrations in the filtrates were analysed. 
The soils in the five testing groups were sampled, oven-dried and fractionated by a six-step procedure (Luo et al., 2021). In step 1, $30 \mathrm{ml}$ DI water was mixed with $1.5 \mathrm{~g}$ oven-dried soil for $4 \mathrm{~h}$. After centrifugation ( $3000 \mathrm{rpm}, 5 \mathrm{~min}$ ) and filtration through a $0.45 \mu \mathrm{m}$ mixed cellulose ester membrane filter, the supernatant was digested by $10 \mathrm{ml} \mathrm{K}_{2} \mathrm{~S}_{2} \mathrm{O}_{8}$ for $1 \mathrm{~h}$, and $\mathrm{H}_{2} \mathrm{O}-\mathrm{Pt}$ was tested. The P content in the solutions was measured using a spectrophotometer by testing the developed 'molybdenum blue' at 882 $\mathrm{nm}$ (Fang et al., 2018b). Similarly, the residue sludge was tested in step 2 using $\mathrm{NaHCO}_{3}$ to leach out $\mathrm{NaHCO}_{3}-\mathrm{P}$, step 3 using $\mathrm{NaOH}$ to leach out $\mathrm{NaOH}-\mathrm{P}$, step 4 using $\mathrm{HCl}$ to leach out $\mathrm{HCl}-\mathrm{P}$, step 5 using mixed acid $\left(3 \mathrm{M} \mathrm{HCl}+6 \mathrm{M} \mathrm{H}_{2} \mathrm{SO}_{4}\right.$ ) to leach out mix-P and step 6 using concentrated $\mathrm{H}_{2} \mathrm{SO}_{4}$ and $\mathrm{H}_{2} \mathrm{O}_{2}$ to digest the residue to measure the residual-P.

\section{Data analysis}

Statistical analyses included one-way analysis of variance (ANOVA) and Fisher's Least-Significant Difference (LSD) test. In all cases, a value of $p<0.05$ was considered to be statistically significant compared to the control group.

\section{Results And Discussion}

\section{Characteristics of the RPFs}

The $\mathrm{pH}$ and the contents of SP, CP and BP are presented in Table 1. As shown, SP had the highest $\mathrm{P}$ content, with a value of $63.14 \mathrm{mg} / \mathrm{g}$, followed closely by CaP, with a P content of $61.9 \mathrm{mg} / \mathrm{g}$. The $P$ contents in these two recovered $\mathrm{P}$ products are well within the range of commercial $\mathrm{P}$ fertilizers ( $4 \%$ to 30 wt.\%) (Raptopoulou et al., 2016). BP, in contrast, had the lowest P content of $30.8 \mathrm{mg} / \mathrm{g}$. SP had the highest $\mathrm{pH}$ of 9.5 of these three kinds of RPFs, while CaP and BP were relatively neutral.

As shown in Fig. 1, the crystalline phases of CaP were predominantly $\mathrm{Ca}_{3}\left(\mathrm{PO}_{4}\right)_{2}$ and gypsum (Fang et al. 2018), while SP had the highest purity, with a crystalline phase that was only struvite $\left(\mathrm{Mg}\left(\mathrm{NH}_{4}\right)\right.$ $\left(\mathrm{PO}_{4}\right) \cdot 6 \mathrm{H}_{2} \mathrm{O}$ ) (Wang et al., 2018). BP had the most complex crystalline phases, which included Al-P $\left(\mathrm{AlPO}_{4} \cdot 10 \mathrm{H}_{2} \mathrm{O}\right), \mathrm{Mg}-\mathrm{P}\left(\mathrm{MgHPO}_{4}\right)$, and Ca-P $\left(\mathrm{Ca}_{15}\left(\mathrm{PO}_{4}\right)_{2}\left(\mathrm{SiO}_{4}\right)_{6}\right)$ (Fang et al., 2019). The microstructure of these RPFs is shown in Fig. 2. $\mathrm{CaP}$ has dense flakes that consist of $\mathrm{Fe}, \mathrm{Ca}, \mathrm{P}$ and $\mathrm{Al}$; $\mathrm{SP}$ has a rod-like surface that consists of $\mathrm{Mg}, \mathrm{P}$ and $\mathrm{Cl} ; \mathrm{BP}$ has a loose and porous structure with globular-like precipitates that dominantly consist of $\mathrm{Al}, \mathrm{Mg}, \mathrm{P}$ and $\mathrm{K}$. Their different crystalline $\mathrm{P}$ and microstructure determine their different $P$ effects in soils; for example, the microstructure of BP has the potential to enhance the physical characteristics of the matrix by controlling water flow (Pogorzelski et al., 2020).

In addition, trace elements in nutrients are known to pose a risk of potential accumulation in soils and can be transferred via the food chain (Jiao et al., 2012). Excessive concentrations of trace elements in soil or nutrient solutions are essentially toxic to living organisms and growing plants. Table S1 shows the 
regulation limits of trace elements for fertilizers in different countries. Comparing the values in Table 1 and Table S1, except for CaP, the contents of trace elements in BP and SP were within the limits of the fertilizer regulations in many countries. SP has the highest purity among these three RPFs with the lowest level of heavy metals. In $\mathrm{CaP}$, the content of $\mathrm{Cd}$ was slightly higher than the limit, which might be due to the precipitation of $\mathrm{Cd}(\mathrm{OH})_{2}$ during the $\mathrm{pH}$ adjustment process.

In sum, the P contents of SP and CaP were similar, twice the BP P content. CaP has the most trace elements and a dense structure, while SP has the highest purity, and its content is dominantly struvite. BP has the most complex content, but it has the most porous microstructure.

Growth status of the plants

The growth statuses of choy sum and ryegrass are presented in Fig. 3. For choy sum, the worst growth status was in the BC (control) group, since the leaf number (Fig. S1), size (Fig. S2) and shoot length were the lowest among the different treatment groups. The leaves in the BC group even turned yellow and became seriously withered by the end of the growth period, which suggested that the other four groups were effectively fertilized. In comparison, SP performed best among all of the P fertilized groups. Similarly, the ryegrass in the $\mathrm{BC}$ (control) group was paler and thinner than that in the other $\mathrm{P}$ fertilization groups and was dark green in colour. In addition, the BP group had the highest germination rate, mostly because biochar increased the soil amelioration effect (Yuan and $\mathrm{Xu}, 2015)$, while the other two kinds of RPFs exhibited germination rates similar to those of the CoP group.

To further compare the agronomic effectiveness of the RPFs, the indicators of plant growth, including shoot height and weight, were determined after harvest. From Table 2 and Fig. 4, the average shoot length of the choy sum in the BC group was $7.2 \mathrm{~cm}$, which was significantly increased to 15.9, 15.5, 17.0 and $16.2 \mathrm{~cm}$ after the application of MP, CaP, SP and BP, respectively. Therefore, the addition of $\mathrm{P}$ fertilizers played a fundamental role in the growth of choy sum and could significantly increase the shoot length. As shown, the effect of the RPFs was comparable or slightly superior to MP in terms of shoot length. However, no significant differences were observed in the shoot length among the different RPFs used.

For the plant weight, significant differences in the biomass production of the choy sum were found among different treatments with that of the BC. Specifically, the application of BP and SP resulted in the highest fresh and dry weights of choy sum, closely followed by MP (Table 2). In contrast, CaP was the least effective among the three RPFs. This might be due to its low solubility, dense structure and the presence of a large amount of $\mathrm{CaSO}_{4}$, which decreased the $\mathrm{P}$ accessibility. In addition, CaP had the highest contents of $\mathrm{Al}$ and $\mathrm{Cd}$ among these three RPFs, which would impair the health of the plants (Thomsen et al., 2017). Consistently, the dry weight of the choy sum fertilized with CaP was significantly lower than those fertilized with BP and SP. Despite this, the fresh weight and dry weight of the shoots in the RPF group were significantly higher than those in the BC group. Interestingly, SP produced a higher fresh weight, although it was applied at the same amount. This might be attributed to the Mg involved and the high bioavailability of SP. Similar results were obtained when struvite was applied to cultivate 
lettuce, which was attributed to the high amount of $\mathrm{Mg}$ incorporated into struvite and its synergistic effect on P uptake (Lo and Gonza, 2009). Magnesium is an essential component of the chlorophyll molecule; thus, it plays a critical role in photosynthesis (Lo and Gonza, 2009). This could be reflected in Fig. 4b, since SP produced the highest chlorophyll content, confirming that Mg played a significant role in photosynthesis by the plant.

Table 2 Growth indicators of plants

\begin{tabular}{|llllll|}
\hline Items & BC & MP/CoP & CaP & SP & BP \\
\hline Choy sum & & & & & \\
\hline Fresh weight (g/shoot) & $0.23 \mathrm{~b}$ & $2.79 \mathrm{a}$ & $2.49 \mathrm{a}$ & $2.96 \mathrm{a}$ & $2.93 \mathrm{a}$ \\
\hline Dry weight (g/shoot) & $0.029 \mathrm{c}$ & $0.16 \mathrm{a}, \mathrm{b}$ & $0.13 \mathrm{~b}$ & $0.18 \mathrm{a}$ & $0.23 \mathrm{a}$ \\
\hline Shoot length (cm/shoot) & $7.2 \mathrm{~b}$ & $15.9 \mathrm{a}$ & $15.5 \mathrm{a}$ & $17.0 \mathrm{a}$ & $16.2 \mathrm{a}$ \\
\hline Chlorophyll contents & 1.016 & 2.04 & 1.85 & 2.05 & 1.83 \\
\hline Leaf number & 6 & 10 & 9 & 11 & 9 \\
\hline Ryegrass & & & & & \\
\hline Fresh weight (mg/shoot) & $18.5 \mathrm{c}$ & $26.6 \mathrm{a}, \mathrm{b}$ & $20.9 \mathrm{~b}$ & $29.2 \mathrm{a}$ & $21.8 \mathrm{~b}$ \\
\hline Dry weight (mg/shoot) & $2.6 \mathrm{c}$ & $3.6 \mathrm{a}$ & $2.9 \mathrm{~b}, \mathrm{c}$ & $3.0 \mathrm{~b}$ & $3.0 \mathrm{~b}$ \\
\hline Shoot length (cm) & $13.0 \mathrm{c}$ & $13.4 \mathrm{~b}$ & $13.4 \mathrm{~b}$ & $13.4 \mathrm{~b}$ & $13.7 \mathrm{a}$ \\
\hline Root length (cm) & $0.8 \mathrm{c}$ & $1.2 \mathrm{~b}$ & $1.0 \mathrm{~b}$ & $1.1 \mathrm{~b}$ & $1.5 \mathrm{a}$ \\
\hline Chlorophyll content (mg/g) & $1.01 \mathrm{~d}$ & $2.09 \mathrm{c}$ & $2.15 \mathrm{~b}$ & $2.05 \mathrm{c}$ & $2.42 \mathrm{a}$ \\
\hline Notes: Different lowercase letter means the result are statically different at $\mathrm{p}<0.05$. \\
\hline
\end{tabular}

In the case of ryegrass, BP pots had the highest shoot length with an average value of $13.7 \mathrm{~cm}$, closely followed by CoP, SP and CaP pots with similar values $(13.4 \mathrm{~cm})$. As expected, the ryegrass in the control group had the shortest average shoot length $(13.0 \mathrm{~cm})$ due to its lack of $P$. In addition, the root system of the BP group was obviously better developed and was longer than that of the other groups, while the BC group had the shortest and worse developed roots. The fresh weight of the plants followed the order SP > $\mathrm{CoP}>\mathrm{BP}>\mathrm{CaP}>\mathrm{BC}$. Specifically, the fresh weight of the SP group was $29.2 \mathrm{mg}$, which was $25 \%$ and $36 \%$ higher than those of $\mathrm{BP}$ and $\mathrm{BC}$, respectively. As expected, ryegrass in the SP group had the highest chlorophyll content. It should be noted that due to the relatively small amount of ryegrass after harvest, the dried masses of all pots were all low and similar.

Overall, SP containing a high content of Mg was beneficial for the photosynthesis of chlorophyll, thus promoting the growth of plants. BP also stimulated the growth of plants (especially for the root systems) due to its highly porous structure and the additional nutrient elements in the biochar. The agronomic effectiveness of BP and SP were comparable to or even better than that of CoP as a P source for the 
cultivation of ryegrass. The agronomic effectiveness of CaP was slightly lower than that of CoP but significantly better than that of the BC group. Even though inferior to other $\mathrm{P}$ fertilizers, CaP could still be regarded as a potential $P$ source due to its growth-promoting effect on ryegrass.

$P$ uptake and the accumulation of heavy metals by plants

\section{$P$ release by $P$ fertilizers}

After application to soils, RPFs/P fertilizers release $\mathrm{P}$ through dissolution and reactions with plants and microorganisms. Under the same abiotic and biotic factors, the soil P levels can reflect the transformation of different RPF fertilization schemes (Ning et al., 2020).

Figure 5 shows that the total $\mathrm{P}$ of the $\mathrm{BC}$ group was the lowest, and the other $4 \mathrm{P}$ fertilization groups had similar total $\mathrm{P}$ contents. The labile $\mathrm{P}$ of the $\mathrm{BC}$ group was also the lowest, which explained why the plants in the $\mathrm{BC}$ group grew poorly. Although the total $\mathrm{P}$ of $\mathrm{BP}$ was not the highest, its labile $\mathrm{P}\left(\mathrm{H}_{2} \mathrm{O}-\mathrm{P}\right.$ and $\mathrm{NaHCO}_{3}-\mathrm{P}$ ) was comparable to that of SP. This is consistent with the planting result, in which BP had the thickest plant growth. Specifically, the $\mathrm{NaHCO}_{3}-\mathrm{P}$ of $\mathrm{BP}$ was the most abundant among these four groups. The CaP group had the lowest labile $\mathrm{P}$ among these four P-fertilized groups, which can be explained by its dense structure, and $\mathrm{Ca}_{3}\left(\mathrm{PO}_{4}\right)_{2}$ had low plant availability, as alluded to in Sect. 3.1. In addition, the residual $\mathrm{P}$ of $\mathrm{BP}$ was the lowest among these four fertilized groups, while the CoP was the highest.

All of these results indicated that these three kinds of RPFs had comparable P effects relative to CoP. BP had the highest $P$ availability with more labile $P$ and the least residual $P$.

\section{P uptake by plants}

Figure 6a shows the P content in choy sum shoots after harvest using different $\mathrm{P}$ sources. The BC pots undoubtedly had the lowest $P$ content, which was far lower than the other groups, consistent with the alluded $\mathrm{P}$ contents. Enormous differences in shoot $\mathrm{P}$ content were observed despite the equal $\mathrm{P}$ application rate at the beginning of the cultivation. The MP pots had the highest $P$ content with a value of $6.25 \mathrm{mg} / \mathrm{kg}$, mostly due to the high P solubility of MP. SP and BP had similar P contents of 5.32 and 4.76 $\mathrm{mg} / \mathrm{kg}$, respectively. The CaP pots only had $3.33 \mathrm{mg} / \mathrm{kg}$. This was attributed to the lowest total $P$ and labile P of CaP compared with SP, BP and MP.

Figure $6 \mathrm{~b}$ shows the $\mathrm{P}$ contents in the five groups of ryegrass. The highest uptake efficiency was attained by the BP group. In addition to the improvement of germination rates, the high plant availability of BP is attributed to its more labile-P and highly porous structure, which provides more sites for contacting microorganisms (Ahmad et al., 2014). The P uptake of the CaP group was the lowest among the three RPFs but it was still higher than that of the BC group, which might be due to its least labile-P and dense structure. In contrast with the SP and BP groups, all three kinds of RPFs had remarkable P uptake by ryegrass, which demonstrated their acceptable $P$ availability.

\section{Accumulation of heavy metals}


The metal contents in the choy sum shoots and ryegrass were determined and are shown in Fig. 7. The released phosphorus $\left(\mathrm{PO}_{4}{ }^{3-}\right)$, nitrogen $\left(\mathrm{NH}^{4+}\right)$ and magnesium $(\mathrm{Mg})$ can be adsorbed simultaneously by plants along with any released metals. The detected metals were different between these two kinds of plants due to their different growth characteristics. The metal content in the dried choy sum shoot (Fig. 7a) followed the order of $\mathrm{Zn}>\mathrm{Cu}>\mathrm{Cd}>\mathrm{Pb}>\mathrm{Co} \approx \mathrm{As}$ in the different treatment groups. The As contents in all fertilized pots were similar and within the range of $0.19 \sim 0.23 \mathrm{mg} / \mathrm{kg}$. Similarly, the Co contents were comparable within the range of $0.25 \sim 0.45$. The $\mathrm{Cd}$ and $\mathrm{Cu}$ contents in the fertilized pots were also comparable. Specifically, both the SP and BP pots had lower Cd contents than the MP pots, and the $\mathrm{CaP}$ pots had the highest $\mathrm{Cd}$ content. For $\mathrm{Cu}$, the $\mathrm{CaP}$ and $\mathrm{BP}$ pots had relatively lower contents than the SP and MP pots. In contrast, significant differences were observed for the $\mathrm{Zn}$ contents in the different pots. The MP pots had the highest Zn content with an average value of $75.05 \mathrm{mg} / \mathrm{kg}$, followed by CaP, BP and SP. The Zn content in the SP pots was $24.98 \mathrm{mg} / \mathrm{kg}$, which was significantly lower than that in the other pots.

These results indicated that the contents of heavy metals in choy sum met the limits regulated by the FAO/WHO and several other countries (Table 3). This reveals that the utilization of these RPFs to cultivate choy sum does not endanger human health through heavy metal accumulation in plants. In summary, the comparable or even lower heavy metal contents in the RPF pots indicated that they could be safe for choy sum cultivation.

The uptake of various metals by ryegrasses is shown in Fig. 7b. No obvious differences were found in heavy metal contents among the three kinds of RPFs along with the CoP and BC cultivated ryegrass. This might be due to the trace amounts of heavy metals in the natural soils and the low plant availability for the metals in the fertilizers. The relatively lower heavy metal contents found in the BP group might be attributed to its porous structure with a high adsorption capacity for heavy metals (Ahmad et al., 2014; M et al., 2014). In particular, the Al content of the BP group was the lowest because the organic compounds of BP can decrease the Al content (Pogorzelski et al., 2020). Although these three kinds of RPFs contained higher contents of metals, no obvious increase in the metal contents was found in their cultivated plants, such as $\mathrm{Zn}, \mathrm{Fe}, \mathrm{Mg}$, etc.

For animal feed, only $\mathrm{As}(<4 \mathrm{mg} / \mathrm{kg}), \mathrm{Cd}(<1 \mathrm{mg} / \mathrm{kg})$ and $\mathrm{Pb}(<30 \mathrm{mg} / \mathrm{kg})$ are regulated as the maximum allowable concentration in ryegrass with a moisture content of $12 \%$ (EC, 2002; Healy et al., 2016). However, in this study, the maximum contents of these elements were As $(2.8 \mathrm{mg} / \mathrm{kg}), \mathrm{Pb}(7.8 \mathrm{mg} / \mathrm{kg})$ and $\mathrm{Cd}$ (below the detection limit), which are much lower than the limits stipulated in the regulations.

Table 3 Ranges and safe limits of heavy metals in Brassica vegetable family cultivated using RPFs ( $\mathrm{mg} / \mathrm{kg}$ dry weight) 


\begin{tabular}{|c|c|c|c|c|c|c|}
\hline \multirow[t]{2}{*}{ Items } & \multirow{2}{*}{$\begin{array}{l}\text { (Ryu et al., } \\
\text { 2012) }\end{array}$} & \multirow{2}{*}{$\begin{array}{l}\text { (Ryu and Lee, } \\
\text { 2016) }\end{array}$} & \multirow{2}{*}{$\begin{array}{l}\text { This } \\
\text { study }\end{array}$} & \multicolumn{3}{|l|}{ Safe limits } \\
\hline & & & & $\begin{array}{l}\text { (SFDA, } \\
\text { 2017) }\end{array}$ & $\begin{array}{l}\text { (FAO/WHO, } \\
\text { 2015) }\end{array}$ & $\begin{array}{l}\text { (RC and } \mathrm{A} \text {, } \\
\text { 2015) }\end{array}$ \\
\hline $\mathrm{Zn}$ & 121.0 & 68.0 & $\begin{array}{l}24.98 \sim \\
60.73\end{array}$ & & & 60 \\
\hline $\mathrm{Cu}$ & 7.2 & 20.5 & $\begin{array}{l}7.38 \sim ~ \\
8.94\end{array}$ & & & 40 \\
\hline Co & & & $\begin{array}{l}0.27 \sim \\
0.45\end{array}$ & & & $0.05 \sim 0.1$ \\
\hline As & n.d. & n.d. & $\begin{array}{l}0.19 \sim \\
0.22\end{array}$ & 0.5 & & 0.2 \\
\hline $\mathrm{Cd}$ & n.d. & n.d. & $\begin{array}{l}0.47 \sim \\
1.20\end{array}$ & $0.05 \sim 0.2$ & $0.02 \sim 0.2$ & 0.3 \\
\hline $\mathrm{Pb}$ & n.d. & 4.5 & $\begin{array}{l}0.13 \sim \\
0.40\end{array}$ & $0.1 \sim 0.3$ & $0.05 \sim 0.3$ & $0.2 / 0.3$ \\
\hline
\end{tabular}

\section{Conclusions}

Recovering P as fertilizer from ISSA not only sustains the global P cycle but is also beneficial to ISSA management. The three studied RPFs are three kinds of representative products recovered from ISSA through wet-extraction methods, which contained significant amounts of $\mathrm{P}$ within the commercial fertilizer range. This study demonstrated that RPFs produced from ISSA exhibited comparable/better agronomic effectiveness for the growth of choy sum and ryegrass than commercial MP/CoP due to their similar P effects in soils. BP significantly enhanced the germination rate of ryegrasses in soil cultivation due to its high labile-P and porous structure; struvite effectively facilitated the growth of choy sum in a hydroponic environment due to its high purity. Negligible/no heavy metal contamination was found in the cultivated plants, indicating no risk of using RPFs from ISSA. In general, recovering P as struvite or adsorbing $P$ from the acid extract of ISSA using biochar are preferred options for producing fertilizers from ISSA. Due to the different $\mathrm{pH}$ values and physical characteristics of these two kinds of RPFs, their effects on the soil profile in long-term processes still needs further study.

\section{Declarations}

\section{Acknowledgements}

The authors would like to thank the Hong Kong Research Grants Council (PolyU 152132/14E) and the National Natural Science Foundation of China/Hong Kong Research Grants Council Joint Research Scheme (N_PolyU511/18) for financial support.

\section{Declaration of Interest Statement}


I, Le FANG, on behalf of all authors, declared that there are no known conflicts of interest to this publication.

I declare that we do not have any commercial or associative interest that represents a conflict of interest in connection with the manuscript submitted.

Le FANG

$12^{\text {th }}$ July 2021

\section{References}

1. Ahmad M, Rajapaksha AU, Lim JE, Zhang M, Bolan N, Mohan D, Vithanage M, Lee SS, Ok YS (2014) Biochar as a sorbent for contaminant management in soil and water: A review. Chemosphere 99:1933. https://doi.org/10.1016/j.chemosphere.2013.10.071

2. Antonini S, Arias MA, Eichert T, Clemens J (2012) Greenhouse evaluation and environmental impact assessment of different urine-derived struvite fertilizers as phosphorus sources for plants. Chemosphere 89(10):1202-1210. https://doi.org/10.1016/j.chemosphere.2012.07.026

3. Börjesson G, Kätterer T (2018) Soil fertility effects of repeated application of sewage sludge in two 30-year-old field experiments. Nutr Cycl Agroecosys 112(3):369-385. https://doi.org/10.1007/s10705-019-09988-x

4. Cavalcante $H$, Araújo F, Noyma NP, Becker V (2018) Phosphorus fractionation in sediments of tropical semiarid reservoirs. Sci Total Environ 619-620, 1022-1029. https://doi.org/10.1016/j.scitotenv.2017.11.204

5. Chen J, Li R, Xia Y, Bai G, Guo P, Wang Z, Zhang H, Siddique KHM (2017) Development of EST-SSR markers in flowering Chinese cabbage (Brassica campestris L. ssp. chinensis var. utilis Tsen et Lee) based on de novo transcriptomic assemblies. PloS one 12(9):e0184736. https://doi.org/10.1371/journal.pone.0184736

6. Cordell D, Drangert JO, White S (2009) The story of phosphorus: Global food security and food for thought. Global Environ Chang 19(2):292-305. https://doi.org/10.1016/j.gloenvcha.2008.10.009

7. Cui J-I, Zhao Y-p, Li J-s, Beiyuan J-z, Tsang DC, Poon C-s, Chan T-s, Wang W-x, Li X-d (2018) Speciation, mobilization, and bioaccessibility of arsenic in geogenic soil profile from Hong Kong. Environ Pollut 232:375-384. https://doi.org/10.1016/j.envpol.2017.09.040

8. de-Bashan LE, Bashan Y (2004) Recent advances in removing phosphorus from wastewater and its future use as fertilizer (1997-2003). Water Res 38(19):4222-4246. https://doi.org/10.1016/j.watres.2004.07.014

9. DeForest DK, Meyer JS (2015) Critical review: toxicity of dietborne metals to aquatic organisms. Crit Rev Env Sci Tec 45(11):1176-1241. https://doi.org/10.1080/10643389.2014.955626

10. Donatello S, Cheeseman CR (2013) Recycling and recovery routes for incinerated sewage sludge ash (ISSA): a review. Waste Manage 33(11):2328-2340. https://doi.org/10.1016/j.wasman.2013.05.024 
11. EC, 2002. Directive 2002/32/EC of the European Parliament and the Council of 7 May 2002 on Undesirable Substances in Animal Feed (OJ L 140)

12. Fang C, Zhang T, Li P, Jiang R-f, Wang Y-c (2014) Application of Magnesium Modified Corn Biochar for Phosphorus Removal and Recovery from Swine Wastewater. Int J Env Res Pub He 11(9):9217. https://doi.org/10.3390/ijerph110909217

13. Fang L, Li J-s, Donatello S, Cheeseman CR, Poon CS, Tsang DCW (2019) Use of Mg/Ca modified biochars to take up phosphorus from acid-extract of incinerated sewage sludge ash (ISSA) for fertilizer application. J Clean Prod 118853. https://doi.org/10.1016/j.jclepro.2019.118853

14. Fang L, Li J-s, Donatello S, Cheeseman CR, Wang Q, Poon CS, Tsang DCW (2018a) Recovery of phosphorus from incinerated sewage sludge ash by combined two-step extraction and selective precipitation. Chem Eng J 348:74-83. https://doi.org/10.1016/j.cej.2018.04.201

15. Fang L, Li J-s, Guo MZ, Cheeseman CR, Tsang DCW, Donatello S, Poon CS (2018b) Phosphorus recovery and leaching of trace elements from incinerated sewage sludge ash (ISSA). Chemosphere 193:278-287. https://doi.org/10.1016/j.chemosphere.2017.11.023

16. Fernandez B, Molina F, Camargo-Valero MA, Pelaez C, González C, Fernández B, Molina F, CamargoValero MA, Peláez C (2021) The Determination of Fertiliser Quality of the Formed Struvite from a WWTP. Water Sci Technol, 2021162. https://doi.org/10.2166/wst.2021.162

17. Franz M (2008) Phosphate fertilizer from sewage sludge ash (SSA). Waste Manage 28(10):18091818. https://doi.org/10.1016/j.wasman.2007.08.011

18. Gorazda K, Tarko B, Wzorek Z, Nowak Anna K, Kulczycka J, Henclik A (2016) Characteristic of wet method of phosphorus recovery from polish sewage sludge ash with nitric acid, Open Chem p 37. https://doi.org/10.1515/chem-2016-0006

19. Gupta DK, Chatterjee S, Datta S, Veer V, Walther C (2014) Role of phosphate fertilizers in heavy metal uptake and detoxification of toxic metals. Chemosphere 108:134-144.

https://doi.org/10.1016/j.chemosphere.2014.01.030

20. Healy MG, Ryan PC, Fenton O, Peyton DP, Wall DP, Morrison L (2016) Bioaccumulation of metals in ryegrass (Lolium perenne L.) following the application of lime stabilised, thermally dried and anaerobically digested sewage sludge. Ecotox Environ Safe 130:303-309. https://doi.org/10.1016/j.ecoenv.2016.04.026

21. Herzel H, Krüger O, Hermann L, Adam C (2016) Sewage sludge ash - A promising secondary phosphorus source for fertilizer production. Sci Total Environ 542:1136-1143. https://doi.org/10.1016/j.scitotenv.2015.08.059

22. Kataki S, West H, Clarke M, Baruah DC (2016) Phosphorus recovery as struvite: Recent concerns for use of seed, alternative Mg source, nitrogen conservation and fertilizer potential. Resour Conserv Recy 107:142-156. https://doi.org/10.1016/j.resconrec.2015.12.009

23. Kratz S, Vogel C, Adam C (2019) Agronomic performance of P recycling fertilizers and methods to predict it: a review. Nutr Cycl Agroecosys 115(1):1-39. https://doi.org/10.1007/s10705-019-10010-7 
24. Krüger O (2016) Recycled fertilizers: Do we need new regulations and analytical methods? Waste Manage 50:1-2. https://doi.org/10.1016/j.wasman.2016.03.017

25. Lee C-G, Alvarez PJJ, Kim H-G, Jeong S, Lee S, Lee KB, Lee S-H, Choi J-W (2018) Phosphorous recovery from sewage sludge using calcium silicate hydrates. Chemosphere 193:1087-1093. https://doi.org/10.1016/j.chemosphere.2017.11.129

26. Lemming C, Bruun S, Jensen LS, Magid J (2017) Plant availability of phosphorus from dewatered sewage sludge, untreated incineration ashes, and other products recovered from a wastewater treatment system. J Plant Nutr Soil Sc 180(6):779-787. https://doi.org/10.1002/jpln.201700206

27. Li B, Bicknell KB, Renwick A (2019) Peak phosphorus, demand trends and implications for the sustainable management of phosphorus in China. Resour Conserv Recy 146:316-328. https://doi.org/10.1016/j.resconrec.2019.03.033

28. Li J, Wei Y, Zhao L, Zhang J, Shangguan Y, Li F, Hou H (2014) Bioaccessibility of antimony and arsenic in highly polluted soils of the mine area and health risk assessment associated with oral ingestion exposure. Ecotox Environ Safe 110:308-315.

https://doi.org/10.1016/j.ecoenv.2014.09.009

29. Li Z, Ma Z, van der Kuijp TJ, Yuan Z, Huang L (2014) A review of soil heavy metal pollution from mines in China: pollution and health risk assessment. Sci Total Environ 468:843-853. https://doi.org/10.1016/j.scitotenv.2013.08.090

30. Liang S, Chen H, Zeng X, Li Z, Yu W, Xiao K, Hu J, Hou H, Liu B, Tao S, Yang J (2019) A comparison between sulfuric acid and oxalic acid leaching with subsequent purification and precipitation for phosphorus recovery from sewage sludge incineration ash. Water Res 159:242-251. https://doi.org/10.1016/j.watres.2019.05.022

31. Luo L, Ye H, Zhang D, Gu J-D, Deng O (2021) The dynamics of phosphorus fractions and the factors driving phosphorus cycle in Zoige Plateau peatland soil. Chemosphere 278:130501. https://doi.org/10.1016/j.chemosphere.2021.130501

32. M A, JE AU,R, L., M, Z., N, B., D, M., M, V., SS, L., YS, O (2014) Biochar as a sorbent for contaminant management in soil and water: A review. Chemosphere 99(3):19-33. https://doi.org/10.1016/j.chemosphere.2013.10.071

33. Meena MD, Yadav RK, Narjary B, Yadav G, Jat HS, Sheoran P, Meena MK, Antil RS, Meena BL, Singh HV, Singh Meena V, Rai PK, Ghosh A, Moharana PC (2019) Municipal solid waste (MSW): Strategies to improve salt affected soil sustainability: A review. Waste Manage 84:38-53. https://doi.org/10.1016/j.wasman.2018.11.020

34. Montemayor E, Bonmatí A, Torrellas M, Camps F, Ortiz C, Domingo F, Riau V, Antón A (2019) Environmental accounting of closed-loop maize production scenarios: Manure as fertilizer and inclusion of catch crops. Resour Conserv Recy 146:395-404. https://doi.org/10.1016/j.resconrec.2019.03.013

35. Nesme T, Withers PJA (2016) Sustainable strategies towards a phosphorus circular economy. Nutr Cycl Agroecosys 104(3):259-264. https://doi.org/10.1007/s10705-016-9774-1 
36. Ning C, Ma Q, Yuan H, Zhou C, Yu W (2020) Mineral fertilizers with recycled manure boost crop yield and $P$ balance in a long-term field trial. Nutr Cycl Agroecosys 116(3):1-13.

https://doi.org/10.1007/s10705-019-10043-y

37. Niu L, Shen Z, Wang C (2011) Sites, pathways, and mechanism of absorption of Cu-EDDS complex in primary roots of maize (Zea mays L.): anatomical, chemical and histochemical analysis. Plant Soil 343(1-2):303-312. https://doi.org/10.1007/s11104-011-0719-9

38. Petzet S, Peplinski B, Bodkhe S, Cornel P (2011) Recovery of phosphorus and aluminium from sewage sludge ash by a new wet chemical elution process (SESAL-Phos-recovery process). Water Sci Technol 64(3):693-699. https://doi.org/10.2166/wst.2011.682

39. Petzet S, Peplinski B, Cornel P (2012) On wet chemical phosphorus recovery from sewage sludge ash by acidic or alkaline leaching and an optimized combination of both. Water Res 46(12):3769-3780. https://doi.org/10.1016/j.watres.2012.03.068

40. Pogorzelski D, Filho JFL, Matias PC, Santos WO, Vergütz L, Melo LCA (2020) Biochar as composite of phosphate fertilizer: Characterization and agronomic effectiveness. Sci Total Environ 743:140604. https://doi.org/10.1016/j.scitotenv.2020.140604

41. Rathika R, Khalifa AYZ, Srinivasan P, Praburaman L, Kamala-Kannan S, Selvankumar T, Kim W, Govarthanan M (2020) Effect of citric acid and vermi-wash on growth and metal accumulation of Sorghum bicolor cultivated in lead and nickel contaminated soil. Chemosphere 243:125327. https://doi.org/10.1016/j.chemosphere.2019.125327

42. Rosemarin A, Ekane N (2016) The governance gap surrounding phosphorus. Nutr Cycl Agroecosys 104(3):265-279. https://doi.org/10.1007/s10705-015-9747-9

43. Senthilkumar K, Mollier A, Delmas M, Pellerin S, Nesme T (2014) Phosphorus recovery and recycling from waste: An appraisal based on a French case study. Resour Conserv Recy 87:97-108. https://doi.org/10.1016/j.resconrec.2014.03.005

44. Shakoor MB, Ye Z-L, Chen S (2021) Engineered biochars for recovering phosphate and ammonium from wastewater: A review. Sci Total Environ 779:146240.

https://doi.org/10.1016/j.scitotenv.2021.146240

45. Steinbeiss S, Gleixner G, Antonietti M (2009) Effect of biochar amendment on soil carbon balance and soil microbial activity. Soil Biol Biochem 41(6):1301-1310. https://doi.org/10.1016/j.soilbio.2009.03.016

46. Thomsen TP, Hauggaard-Nielsen H, Gøbel B, Stoholm P, Ahrenfeldt J, Henriksen UB, Müller-Stöver DS (2017) Low temperature circulating fluidized bed gasification and co-gasification of municipal sewage sludge. Part 2: Evaluation of ash materials as phosphorus fertilizer. Waste Manage 66:145154. https://doi.org/10.1016/j.wasman.2017.04.043

47. Walan P, Davidsson S, Johansson S, Höök M (2014) Phosphate rock production and depletion: Regional disaggregated modeling and global implications. Resour Conserv Recy 93:178-187. https://doi.org/10.1016/j.resconrec.2014.10.011 
48. Wang Q, Li J-s, Tang P, Fang L, Poon CS (2018) Sustainable reclamation of phosphorus from incinerated sewage sludge ash as value-added struvite by chemical extraction, purification and crystallization. J Clean Prod 181:717-725. https://doi.org/10.1016/j.jclepro.2018.01.254

49. Wang R, Fu W, Wang J, Zhu L, Wang L, Wang J, Ahmad Z (2019) Application of Rice Grain Husk Derived Biochar in Ameliorating Toxicity Impacts of $\mathrm{Cu}$ and $\mathrm{Zn}$ on Growth, Physiology and Enzymatic Functioning of Wheat Seedlings. B Environ Contam Tox 103(4):636-641. https://doi.org/10.1007/s00128-019-02705-y

50. Weissengruber L, Möller K, Puschenreiter M, Friedel JK (2018) Long-term soil accumulation of potentially toxic elements and selected organic pollutants through application of recycled phosphorus fertilizers for organic farming conditions. Nutr Cycl Agroecosys 110(3):427-449. https://doi.org/10.1007/s10705-018-9907-9

51. Xu H, He P, Gu W, Wang G, Shao L (2012) Recovery of phosphorus as struvite from sewage sludge ash. J Environ Sci 24(8):1533-1538. https://doi.org/10.1016/S1001-0742(11)60969-8

52. Yao Y, Gao B, Chen J, Zhang M, Inyang M, Li Y, Alva A, Yang L (2013) Engineered carbon (biochar) prepared by direct pyrolysis of Mg-accumulated tomato tissues: Characterization and phosphate removal potential. Bioresource Technol 138(6):8-13. https://doi.org/10.1016/j.biortech.2013.03.057

53. Yu S, Zhu Y-g, Li X-d (2012) Trace metal contamination in urban soils of China. Sci Total Environ 421:17-30. https://doi.org/10.1007/s00128-019-02705-y

54. Yuan JH, Xu RK (2015) The amelioration effects of low temperature biochar generated from nine crop residues on an acidic Ultisol. Soil Use Manage 27(1):110-115. https://doi.org/10.1111/j.14752743.2010.00317.x

55. Zhao Y-p, Cui J-I, Chan T-s, Dong J-c, Chen D-I, Li X-d (2018) Role of chelant on Cu distribution and speciation in Lolium multiflorum by synchrotron techniques. Sci Total Environ 621:772-781. https://doi.org/10.1016/j.scitotenv.2017.11.189

56. Zin T, Kim MM, D.-J (2019) Struvite production from food processing wastewater and incinerated sewage sludge ash as an alternative $\mathrm{N}$ and $\mathrm{P}$ source: Optimization of multiple resources recovery by response surface methodology. Process Saf Environ 126:242-249. https://doi.org/10.1016/j.psep.2019.04.018

\section{Figures}


1-AlphaCa $3\left(\mathrm{PO}_{4}\right)_{2} 2-\mathrm{SiO}_{2} 3-\mathrm{Mg}(\mathrm{OH})_{2} 4-\mathrm{Ca}_{15}\left(\mathrm{PO}_{4}\right)_{2}(\mathrm{OH})_{8}-4 \mathrm{H}_{2} \mathrm{O}$ 5-Gypsum

6-Struvite 7- $\mathrm{AlPO}_{4} \mathrm{IOH}_{2} \mathrm{O} 8-\mathrm{MgHPO}_{4}\left(\mathrm{H}_{2} \mathrm{O}\right)_{3} 9-\mathrm{Ca}_{15}\left(\mathrm{PO}_{4}\right)_{2}\left(\mathrm{SiO}_{4}\right)_{6}$

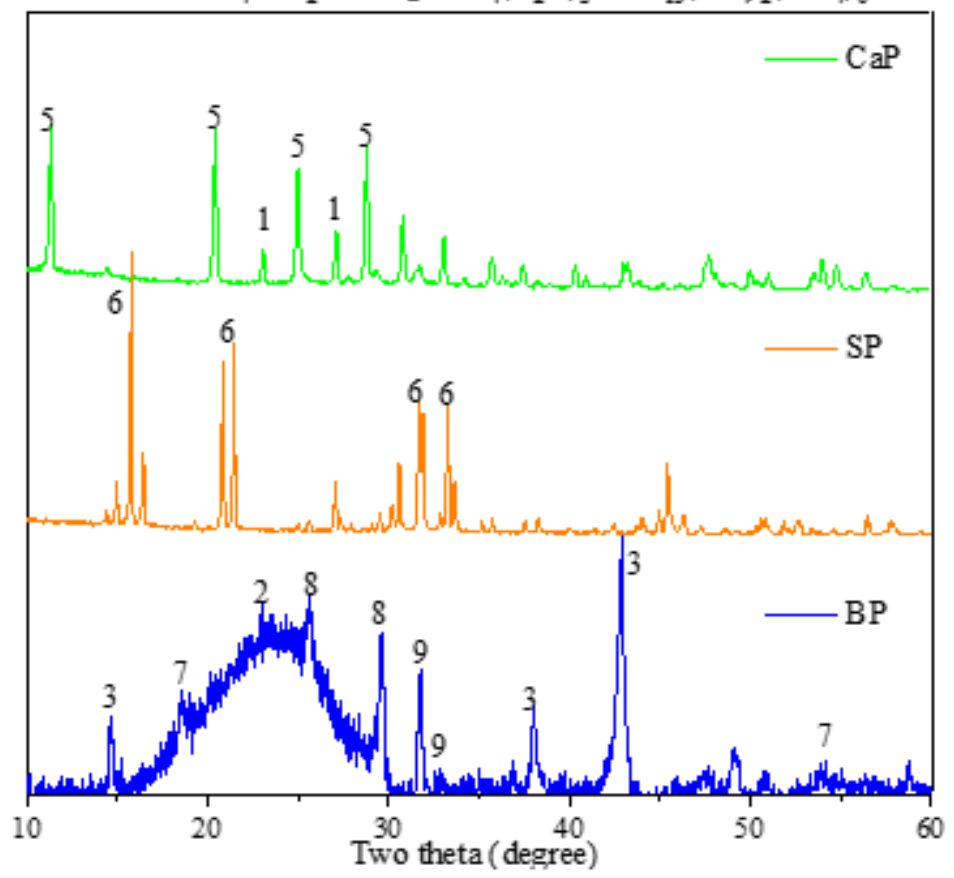

Figure 1

XRD of three kinds of RPFs

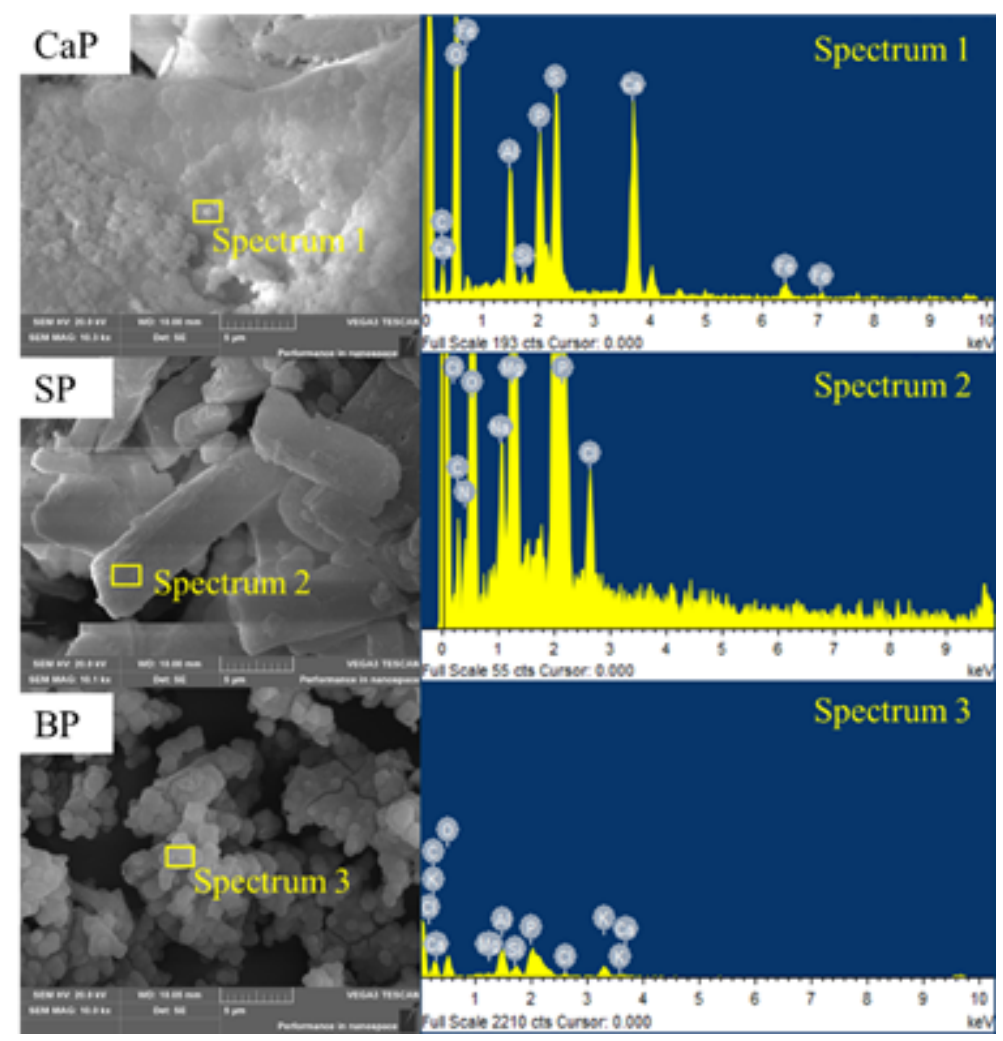

Figure 2

SEM-EDX analysis of three kinds of RPFs 

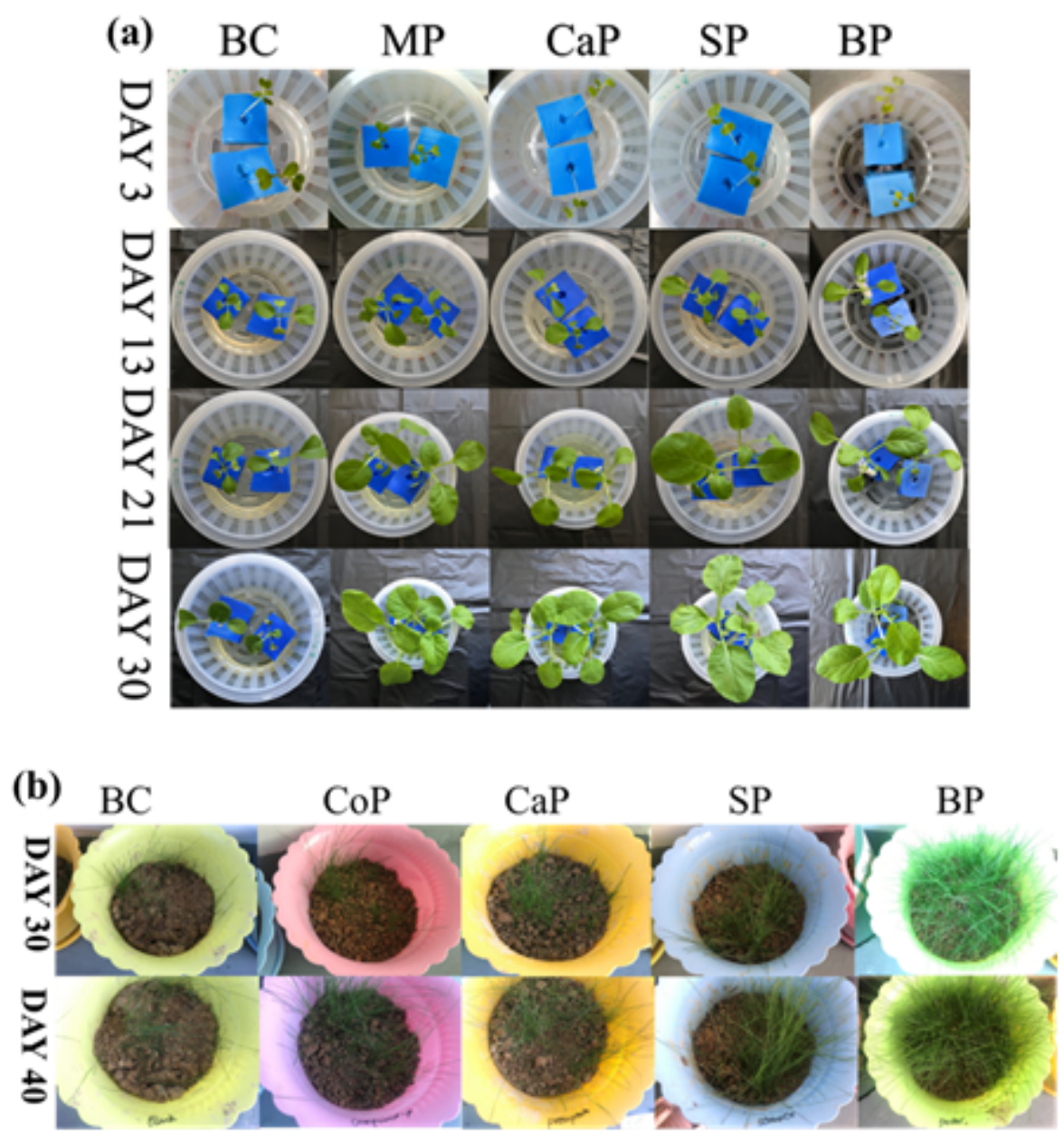

Figure 3

Growth status of (a) choy sum at day 7, 13, 21 and 30 and (b) ryegrass at day 30 and 40. 

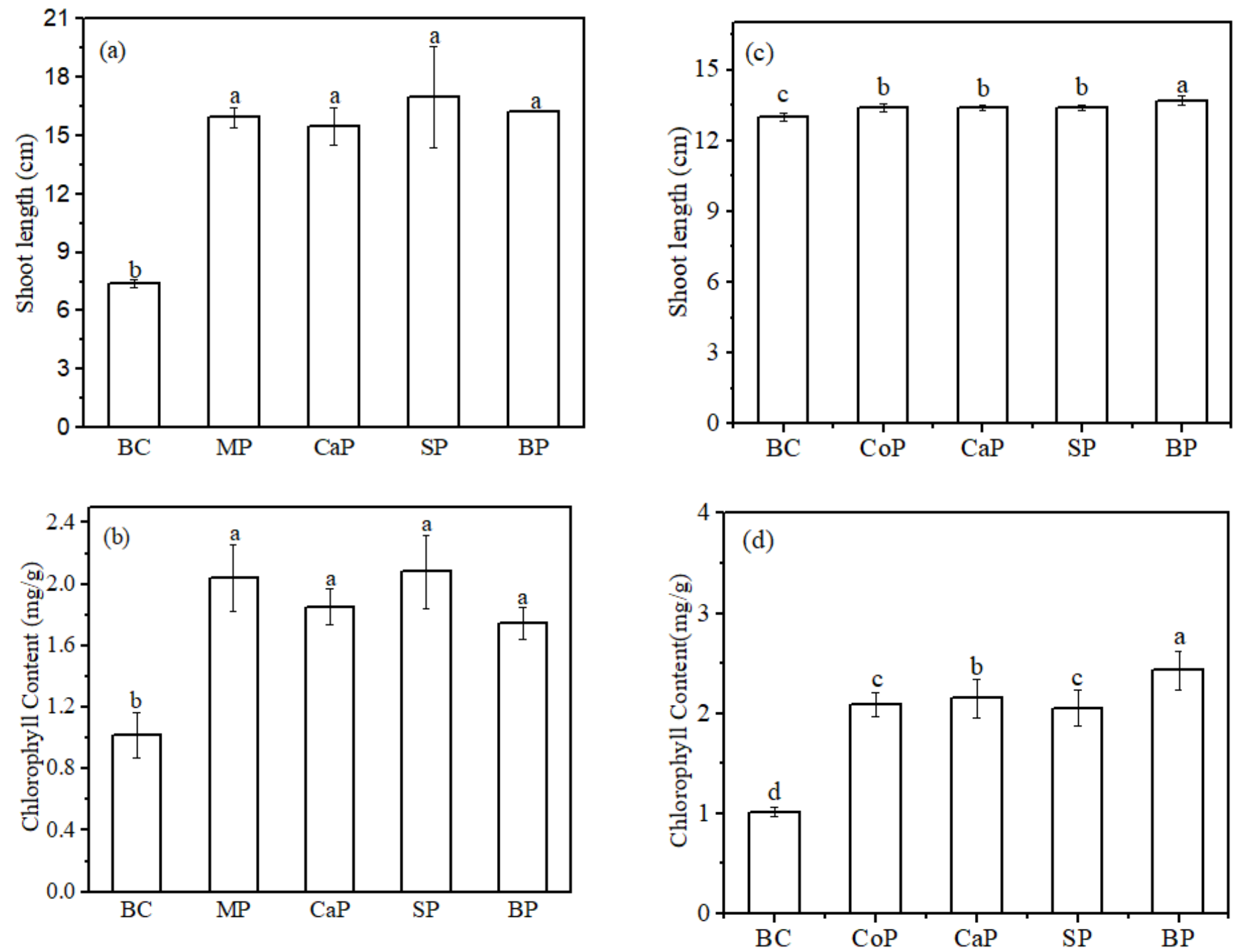

Figure 4

Shoot lengths and chlorophyll contents of choy sum ( $a$ and b) and ryegrass (c and d). 

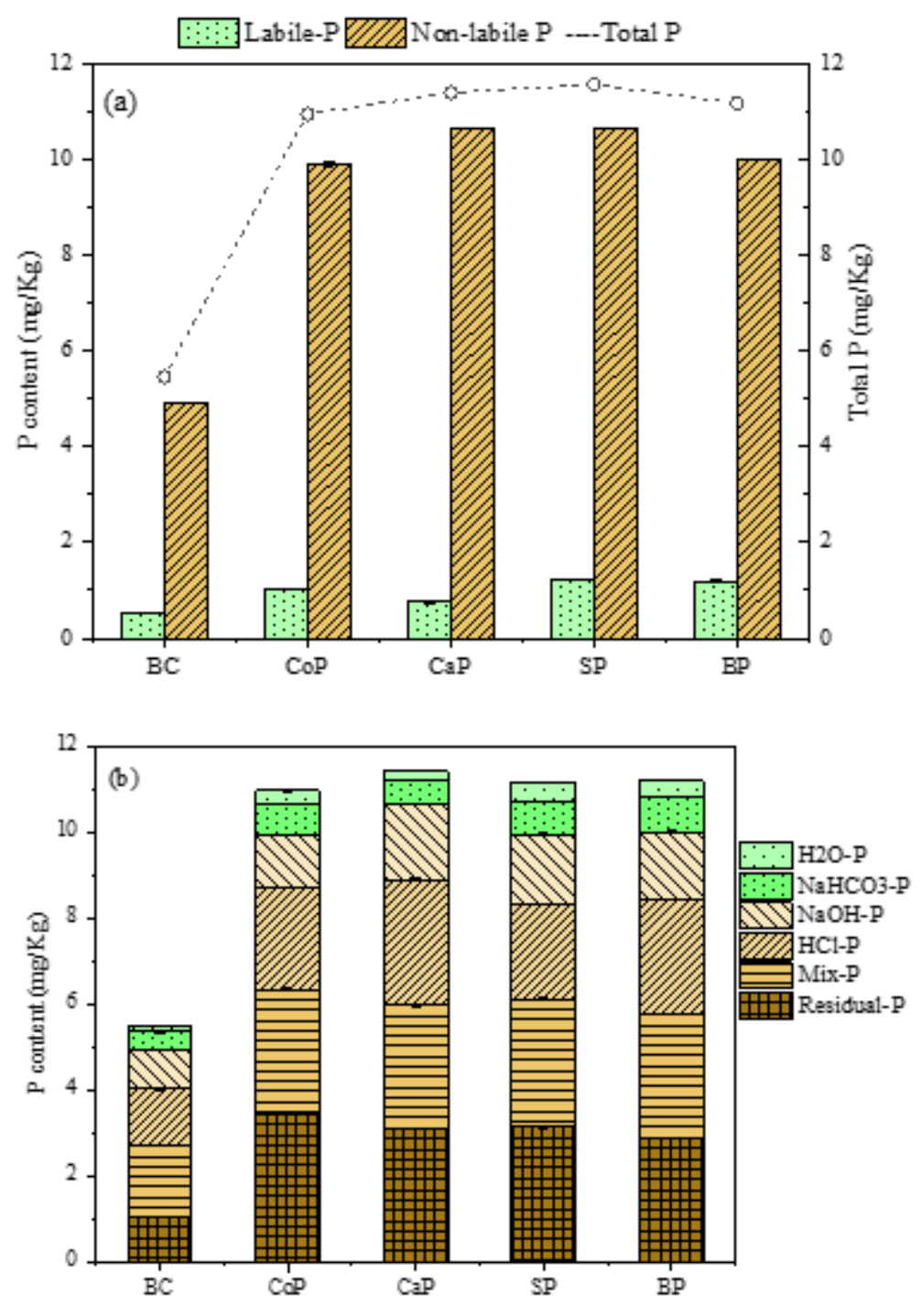

Figure 5

The labile-P and non-labile P contents (a) and the P fractions (b) of soils in different groups 

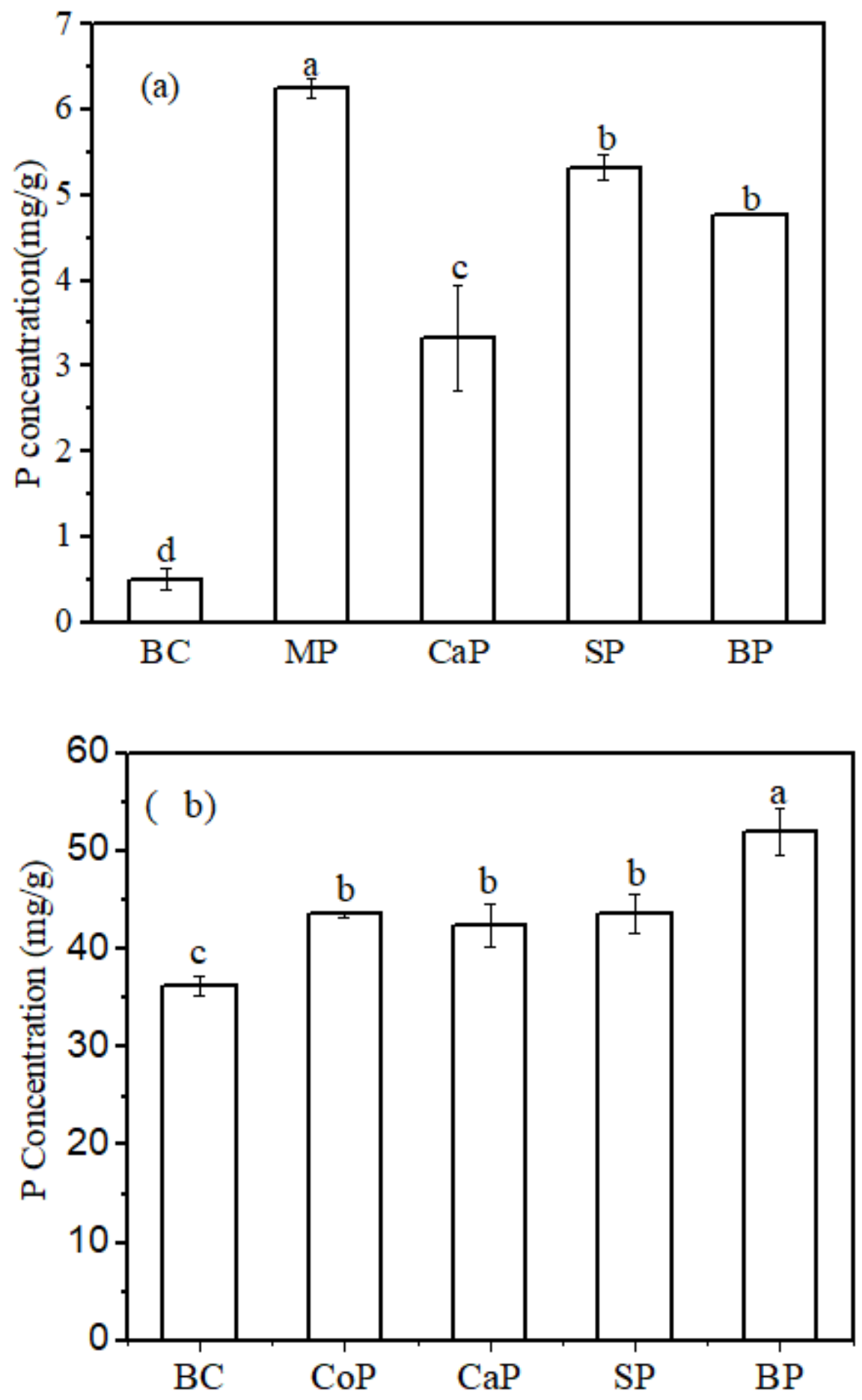

Figure 6

P contents in the dried choy sum shoot (a) and ryegrass (b). 

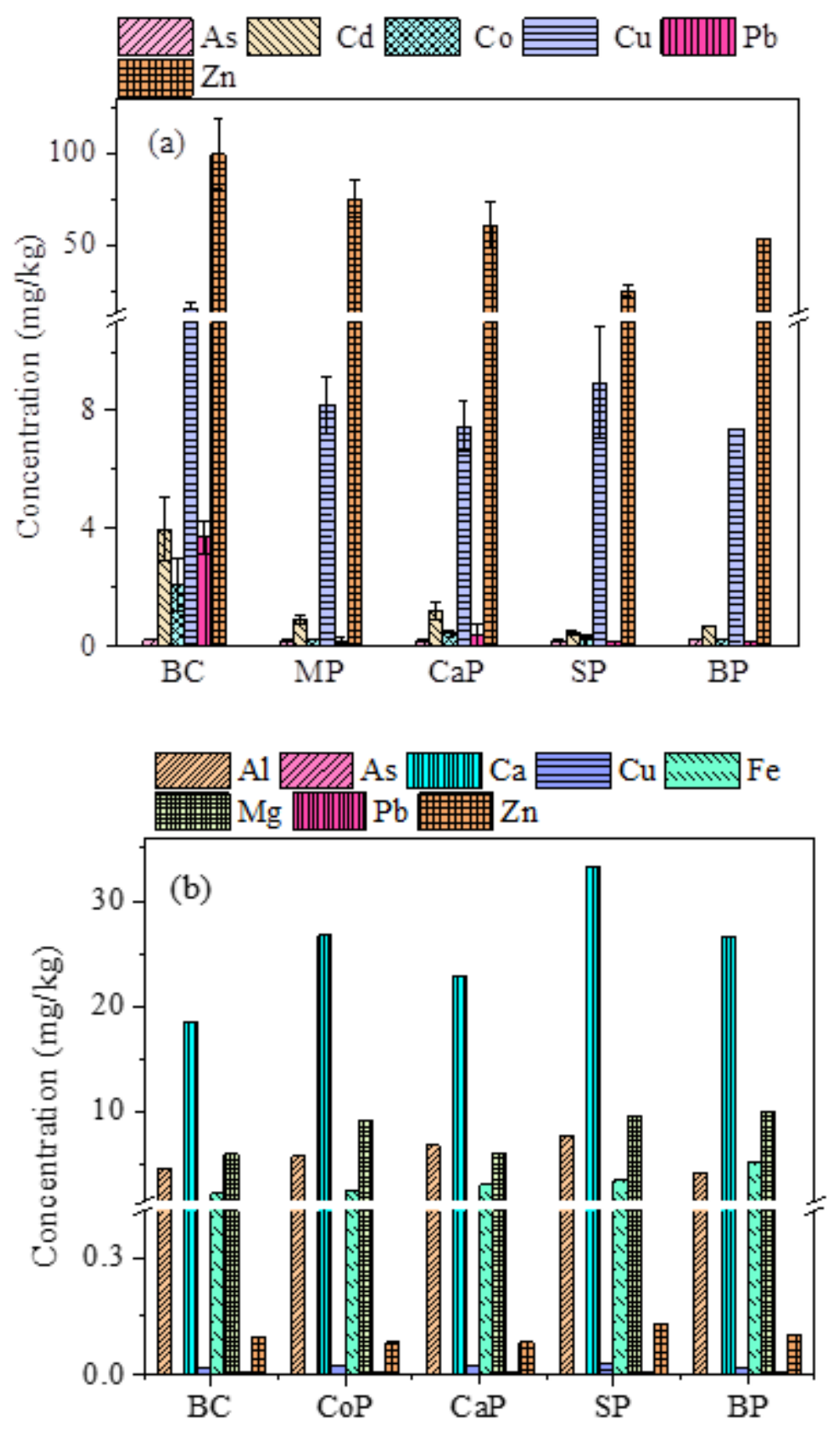

Figure 7

Uptake of heavy metals by choy sum shoot (a) and ryegrass (b).

\section{Supplementary Files}

This is a list of supplementary files associated with this preprint. Click to download.

- floatimage1.png

- Supplementary.docx 